\title{
Numerical and Analytical Modeling of Permanent Deformations in Panels Made of Nanomodified Carbon Fiber Reinforced Plastic with Asymmetric Packing
}

\author{
S. Radaev, \\ Moscow Aviation Institute (National Research University), \\ Moscow, Volokolamskoe shosse 4, 125993 , \\ Russian Federation
}

Received: February 9, 2021. Revised: August 1, 2021. Accepted: September 8, 2021. Published: September 10, 2021.

\begin{abstract}
In this paper, a mathematical model of a multilayer panel made of nanomodified carbon fiber reinforced plastic with asymmetric packing is proposed. The introduction of nanosized particles into the composition of the composite or its components (fiber or binder) allows not only to increase its physical and mechanical properties, but also to improve the picture of the residual stress-strain state.

The paper investigates the effect of nanomodification of carbon fiber reinforced plastic on the residual stress-strain state after molding using numerical and analytical methods. Numerous results of computational experiments have been obtained. The results of numerical and analytical modeling are compared with experimental data. Conclusions are drawn about the possibility of reducing the residual stress-strain state in structures with asymmetric reinforcement schemes when using a matrix containing carbon nanoparticles. A mathematical model of a multilayer panel made of nano-modified carbon fiber with asymmetric packing has been built.

Investigation of the residual stress-strain state of structural elements made of carbon fiber reinforced plastic made it possible to reveal the possibility of reducing the residual stress-strain state and leash in structures with asymmetric reinforcement schemes when using a matrix containing carbon nanoparticles.
\end{abstract}

Keywords-Composite material, mathematical modeling, nanomodified carbon fiber, stress-strain state, nanoparticles.

\section{INTRODUCTION}

Currently composite materials which have significant advantages over traditional materials such as metals are widely used in various industries in the design of structures for aviation and space technology, mechanical engineering, etc. [1]-[11]. Composite materials have increased specific strength and rigidity, resistance to temperature and vibration loads, as well as low specific gravity, which is especially important in aerospace engineering [12]-[18]. Therefore, the development of modern technology requires the creation of new structural materials with high elastic-strength characteristics, and on their basis, designs with more effective weight data. The creation of polymer composites based on nanomodified binders has recently become one of the priority research areas in the field of composite materials manufacturing technologies. Significant progress has been made in this area [19]-[31]. The development of materials that improve their operational limits is based on the reinforcement of two or more fibers into a single polymer matrix, which leads to an improved material system called hybrid composites with a wide variety of material properties [32]-[41]. When creating nanocomposites, the key tasks are the development of efficient, reliable, and affordable production technologies for mass production, which make it possible to obtain materials with stable characteristics. In this work the study of the influence of nanomodification of carbon fiber on the residual stress-strain state after molding is carried out. As a rule, composites are formed at elevated temperatures, after which they are cooled to the operating temperature. Due to the high anisotropy of physical and mechanical properties during cooling, shrinkage of the composite layers is uneven in thickness and directions. This leads to the appearance of residual deflections and internal 
stresses in composite parts [42]-[52]. One of the ways to reduce residual stresses and strains is nanomodification [53][60]. The introduction of nanosized particles into the composition of the composite or its components (fiber or binder) allows not only to increase its physical and mechanical properties, but also to improve the picture of the residual stress-strain state [61]-[77]. The main task in the work was to determine the degree of influence of nanomodification parameters on the residual stress-strain state. For this purpose, a study was carried out to determine the residual stress-strain state using the proposed mathematical model of a multilayer panel made of nanomodified carbon fiber reinforced plastic with asymmetric packing.

\section{STATEMENT OF THE TASK}

Let us consider a multilayer panel made of a polymer composite, which has anisotropy due to the asymmetry of the properties of the structure of the package along the thickness. The panel in question is free from stress and fastening.

Let us introduce the coordinate system 1,2,3 (Fig. 1) associated with the direction of reinforcement. For unidirectional material, axis 1 is aligned with the direction of the fibers, for woven material, axis 1 is aligned with the direction of the warp thread. Axis 2 is perpendicular to axis 1 and lies in the plane of reinforcement. Axis 3 is directed along the layer thickness and is orthogonal to the layer plane. For the panel, we introduce the $\mathrm{x}, \mathrm{y}, \mathrm{z}$ coordinate system so that the $\mathrm{x}$, $\mathrm{y}$ axes lie in the reinforcement plane, and the $\mathrm{z}$ axis is directed along the thickness of the package.

In the general case, six internal force factors arise in the panel: Nx, Ny, Nxy, Mx, My, Mxy (Fig. 2).

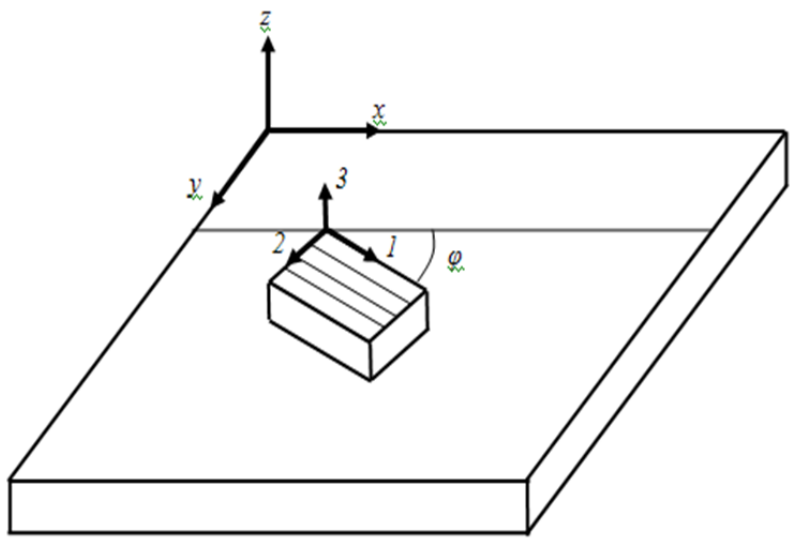

Fig. 1 Coordinate systems of the layer and panel

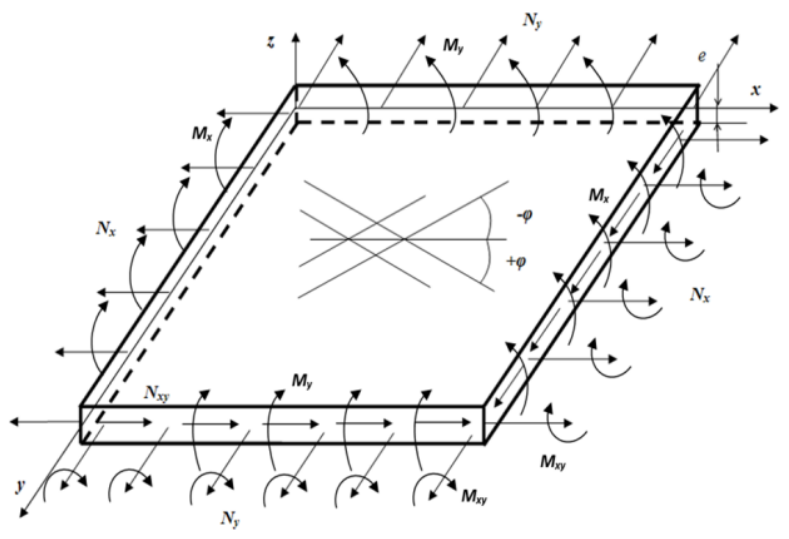

Fig. 2 Geometric model and arising internal force factors of a plate with an asymmetric packet structure

Physical relations in this case will have the following form:

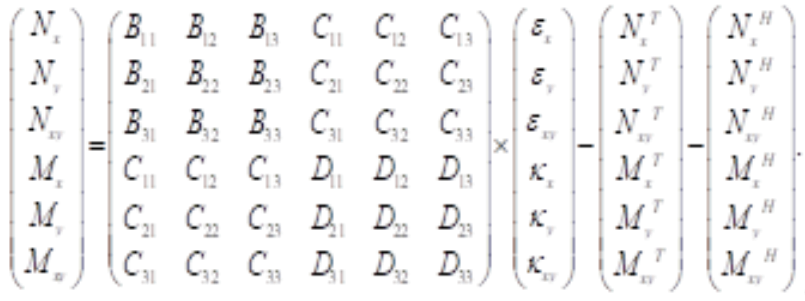

Where $N_{x}^{T}, N_{y}^{T}, N_{x y}^{T}, N_{x}^{H}, N_{y}^{H}, N_{x y}{ }^{H} \quad$ - linear forces caused by thermal deformation (index $\mathrm{T}$ ) and initial tension of layers (index $\mathrm{H}$ );

$$
M_{x}^{T}, M_{y}^{T}, M_{x y}{ }^{T}, M_{x}{ }^{\mu}, M_{y}{ }^{\mu}, M_{x y}{ }^{\mu}
$$

moments caused by thermal deformation (index $\mathrm{T}$ ) and initial tension of layers (index $\mathrm{H}$ );

$$
\begin{aligned}
& B_{m n}, C_{m n}, D_{m n} \text {-generalized package stiffnesses (m, n } \\
& =1,2,3) ; \\
& \quad \varepsilon_{x}, \varepsilon_{y} \varepsilon_{x y} \text { - linear deformations of the package in the }
\end{aligned}
$$
plane of reduction;

$$
\boldsymbol{K}_{x}, \boldsymbol{K}_{y} \boldsymbol{K}_{x y} \text { - curvature of the packet in the plane of }
$$
reduction.

\section{SOLUTION METHOD}

Let us write down the connection between the panel deformation in the reduction plane and the displacements $\mathrm{u} 0$, v0:

$$
\varepsilon_{x}=\frac{\partial u_{0}}{\partial x} ; \varepsilon_{y}=\frac{\partial v_{0}}{\partial y} ; \varepsilon_{x y}=\frac{\partial u_{0}}{\partial y}+\frac{\partial v_{0}}{\partial x}
$$

Relationship of the curvature of the panel to the angles of rotation of the normal $\theta \mathrm{x}, \theta \mathrm{y}$ : 


$$
\kappa_{x}=\frac{\partial \theta_{x}}{\partial x} ; \kappa_{y}=\frac{\partial \theta_{y}}{\partial y} ; \kappa_{x y}=\frac{\partial \theta_{x}}{\partial y}+\frac{\partial \theta_{y}}{\partial x}
$$

The relationship between the angles of rotation of the normal and the deflection $\mathrm{w}$ is as follows:

$$
\theta_{x}=\psi_{x}-\frac{\partial w}{\partial x} ; \theta_{y}=\psi_{y}-\frac{\partial w}{\partial y}
$$

$\psi_{x}, \psi_{y}$ - lateral shears.

The generalized package stiffnesses are defined as follows:

$$
\begin{gathered}
B_{m n}=I_{m n}^{(0)}, \\
C_{m n}=I_{m n}^{(1)}-e I_{m n}^{(0)}, \\
D_{m n}=I_{m n}^{(2)}-2 e I_{m n}^{(1)}+e^{2} I_{m n}^{(0)}, \\
I_{m n}^{(r)}=\int_{0}^{h} b_{m n} Z^{r} d t=\frac{1}{r+1} \sum_{k=1}^{N} b_{m n}^{(k)}\left(Z_{k}^{r+1}-Z_{k-1}^{r+1}\right),
\end{gathered}
$$

Where e - coordinate of the reference plane (for an asymmetric packet, it is chosen arbitrarily);

$$
m, n=1,2,3, r=0,1,2 \text {. }
$$

Let us write expressions for the forces and moments caused by the temperature fields:

$$
\begin{gathered}
N_{x}^{T}=\sum_{j=1}^{3} N_{1 j}^{T}, N_{y}^{T}=\sum_{j=1}^{3} N_{2 j}^{T}, N_{x y}^{T}=\sum_{j=1}^{3} N_{3 j}^{T}, \\
M_{x}^{T}=\sum_{j=1}^{3} M_{1 j}^{T}, M_{y}^{T}=\sum_{j=1}^{3} M_{2 j}^{T}, M_{x y}^{T}=\sum_{j=1}^{3} M_{3 j}^{T},
\end{gathered}
$$

where

$$
\begin{array}{r}
N_{i j}^{T}=\Delta T \sum_{k=1}^{N}\left[b_{i j}{ }^{(k)} \overline{\alpha_{j}^{(k)}}\left(Z_{k}-Z_{k-1}\right)\right] ; \\
M_{i j}^{T}=\Delta T \sum_{k=1}^{N} b_{i j}{ }^{(k)} \overline{\alpha_{j}^{(k)}}\left[\frac{1}{2}\left(Z_{k}{ }^{2}-Z_{k-1}{ }^{2}\right)-e\left(Z_{k}-Z_{k-1}\right)\right] ;
\end{array}
$$

$Z_{k}$ - coordinate of the $k$-th layer, measured from the reference plane; $N$ - number of layers; $b_{i j}{ }^{\left({ }^{k}\right)}$ - linear stiffness of the $k$-th layer reduced to the axes of the panel $(x, y) \quad(i, j=$ $1,2,3) ; \Delta T$ - temperature drop due to cooling; $\bar{\alpha}_{1}{ }^{(k)}, \bar{\alpha}_{2}{ }^{(k)}, \bar{\alpha}_{3}{ }^{(k)}-$ coefficients of linear thermal expansion of the $k$-th layer in the axes of the panel;

Similarly, we write down the efforts and moments from the initial tension:

$$
\begin{aligned}
& N_{x}{ }^{H}=\sum_{j=1}^{3} N_{1 j}^{H}, N_{y}{ }^{H}=\sum_{j=1}^{3} N_{2 j}^{H}, N_{x y}{ }^{H}=\sum_{j=1}^{3} N_{3 j}^{H}, \\
& M_{x}{ }^{H}=\sum_{j=1}^{3} M_{1 j}^{H}, M_{y}{ }^{H}=\sum_{j=1}^{3} M_{2 j}^{H}, M_{x y}{ }^{H}=\sum_{j=1}^{3} M_{3 j}^{H},
\end{aligned}
$$

$$
\begin{aligned}
& \text { where } \quad N_{i j}^{H}=\sum_{k=1}^{N}\left[b_{i j}{ }^{(k)} \overline{\varepsilon_{H j}^{(k)}}\left(Z_{k}-Z_{k-1}\right)\right] ; \\
& M_{i j}^{H}=\sum_{k=1}^{N} b_{i j}^{(k)} \overline{\varepsilon_{H j}^{(k)}}\left[\frac{1}{2}\left(Z_{k}^{2}-Z_{k-1}{ }^{2}\right)-e\left(Z_{k}-Z_{k-1}\right)\right] ; \\
& {\overline{\varepsilon_{H 1}}}^{(k)},{\overline{\varepsilon_{H 2}}}^{(k)}, \overline{\varepsilon_{H 3}}{ }^{(k)}-\text { initial deformations of layers }
\end{aligned}
$$
in the axes of the panel.

Linear stiffnesses for the k-th layer in the case of an asymmetric packet have the following form:

$$
\begin{aligned}
& b_{11}{ }^{(k)}=\left[\overline{E_{1}} m^{4}+\overline{E_{2}} n^{4}+2\left(\overline{E_{1}} v_{12}+2 G_{12}\right) m^{2} n^{2}\right]^{(k)} \\
& b_{22}{ }^{(k)}=\left[\overline{E_{1}} n^{4}+\overline{E_{2}} m^{4}+2\left(\overline{E_{1}} v_{12}+2 G_{12}\right) m^{2} n^{2}\right]^{(k)} \\
& b_{12}{ }^{(k)}=b_{21}{ }^{(k)}=\left[\overline{E_{1}} v_{12}+\left[\overline{E_{1}}+\overline{E_{2}}-2\left(\overline{E_{1}} v_{12}+2 G_{12}\right)\right] m^{2} n^{2}\right]^{(k)} \\
& b_{13}{ }^{(k)}=b_{31}{ }^{(k)}=\left[m n\left[\overline{E_{1}} m^{2}-\overline{E_{2}} n^{2}-\left(\overline{E_{1}} v_{12}+2 G_{12}\right)\left(m^{2}-n^{2}\right)\right]\right]^{(k)}, \\
& b_{23}{ }^{(k)}=b_{32}{ }^{(k)}=\left[m n\left[\overline{E_{1}} n^{2}-\overline{E_{2}} m^{2}+\left(\overline{E_{1}} v_{12}+2 G_{12}\right)\left(m^{2}-n^{2}\right)\right]\right]^{(k)} \\
& \left.b_{33}{ }^{(k)}=\left[\overline{\left(E_{1}\right.}+\overline{E_{2}}-2 \overline{E_{1}} v_{12}\right) m^{2} n^{2}+G_{12}\left(m^{2}-n^{2}\right)\right]^{(k)}
\end{aligned}
$$$$
\begin{aligned}
E_{1}{ }^{(k)} & =\frac{E_{1}{ }^{(k)}}{1-v_{12}{ }^{(k)} v_{21}{ }^{(k)}} \\
E_{2}{ }^{(k)} & =\frac{E_{2}{ }^{(k)}}{1-v_{12}{ }^{(k)} v_{21}{ }^{(k)}}
\end{aligned}
$$

The coefficients of linear thermal expansion for the $\mathrm{k}$-th layer, as well as the layer deformations caused by the initial tension, in the axes of the panel are determined by the appropriate transformation: 


$$
\begin{aligned}
& \left(\frac{\overline{\alpha_{1}}}{\frac{\alpha_{2}}{\alpha_{3}}}\right)^{(k)}=\left(\begin{array}{cc}
m^{2} & n^{2} \\
n^{2} & m^{2} \\
2 m n & -2 m n
\end{array}\right)^{(k)}\left(\begin{array}{l}
\alpha_{1} \\
\alpha_{2}
\end{array}\right)^{(k)}, \\
& \left(\frac{\overline{\varepsilon_{H 1}}}{\frac{\varepsilon_{H 2}}{\varepsilon_{H 3}}}\right)^{(k)}=\left(\begin{array}{c}
m^{2} \\
n^{2} \\
2 m n
\end{array}\right)^{(k)}\left(\varepsilon_{H}\right)^{(k)} .
\end{aligned}
$$

In the formulas above, $\mathrm{m}(\mathrm{k})$ and $\mathrm{n}(\mathrm{k})$ - are trigonometric functions of the orientation angle of the layers $\varphi^{(k)}$ relative to the $\mathrm{x}$-axis of the panel:

$$
\begin{aligned}
& m^{(k)}=\cos \left(\varphi^{(k)}\right), \\
& n^{(k)}=\sin \left(\varphi^{(k)}\right) .
\end{aligned}
$$

We will consider a flat panel without initial curvature with edges free from load and fastening, subject to the action of a temperature field uniformly distributed over the thickness. The reference surface coincides with the middle surface. For the orthotropic structure of the composite $B_{13}=B_{31}=0$, and the coefficients $C_{13}, C_{31}, C_{23}, C_{32}, D_{13}, D_{31}$ are small and can be neglected. Taking this into account, the physical relations for the orthotropic structure of the composite in expanded form take the form:

$$
\begin{aligned}
& \left\{\begin{array}{l}
0=B_{11} \varepsilon_{x}+B_{12} \varepsilon_{y}+C_{11} \kappa_{x}+C_{12} \kappa_{y}-N_{x}{ }^{T}-N_{x}{ }^{H} \\
0=B_{12} \varepsilon_{x}+B_{22} \varepsilon_{y}+C_{21} \kappa_{x}+C_{22} \kappa_{y}-N_{y}{ }^{T}-N_{y}{ }^{H} \\
0=C_{11} \varepsilon_{x}+C_{12} \varepsilon_{y}+D_{11} \kappa_{x}+D_{12} \kappa_{y}-M_{x}{ }^{T}-M_{x}{ }^{H} \\
0=C_{21} \varepsilon_{x}+C_{22} \varepsilon_{y}+D_{21} \kappa_{x}+D_{22} \kappa_{y}-M_{y}{ }^{T}-M_{y}{ }^{H}
\end{array}\right. \\
& \left\{\begin{array}{l}
0=B_{33} \varepsilon_{x y}+C_{33} \kappa_{x y}-N_{x y}{ }^{T}-N_{x y}{ }^{H} \\
0=C_{33} \varepsilon_{x y}+D_{33} \kappa_{x y}-M_{x y}{ }^{T}-M_{x y}{ }^{H}
\end{array}\right.
\end{aligned}
$$

Thus, it is easy to see that in the case of an orthotropic structure of a composite material, the definition of the deformed state is split into two independent problems of finding deflections (curvature component $\boldsymbol{\kappa}_{x}, \boldsymbol{\kappa}_{y}$ ) and twists $\left(\boldsymbol{K}_{x y}\right)$.
The stresses in the layers are determined from Hooke's law using the curvature and deformation components obtained from (1), i.e.

$$
\left(\begin{array}{l}
\sigma_{x} \\
\sigma_{y} \\
\tau_{x y}
\end{array}\right)^{(k)}=\left(\begin{array}{lll}
b_{11} & b_{12} & b_{13} \\
b_{21} & b_{22} & b_{23} \\
b_{31} & b_{32} & b_{33}
\end{array}\right)^{(k)}\left(\begin{array}{c}
\varepsilon_{x}+\kappa_{x} \cdot z_{k}-\bar{\alpha}_{1}^{(k)} \cdot \Delta T-\bar{\varepsilon}_{H 1}^{(k)} \\
\varepsilon_{y}+\kappa_{y} \cdot z_{k}-\bar{a}_{2}^{(k)} \cdot \Delta T-\bar{\varepsilon}^{(k)} \\
\varepsilon_{x y}+\kappa_{x y} \cdot z_{k}-\bar{a}_{3}^{(k)} \cdot \Delta T-\bar{\varepsilon}_{H 3}^{(k)}
\end{array}\right) .
$$

In this case $z_{k}$ is the coordinate of the middle surface of the layer, that is $z_{k}=\left(Z_{k}-e\right)-h_{k} / 2$.

To pass to stresses $\sigma_{1}, \sigma_{2}, \tau_{12}$ in the axes of the layer, it is necessary to use the transformation formulas when rotating the coordinate axes:

$$
\left(\begin{array}{c}
\sigma_{1} \\
\sigma_{2} \\
\tau_{12}
\end{array}\right)^{(k)}=\left(\begin{array}{ccc}
m^{2} & n^{2} & 2 m n \\
n^{2} & m^{2} & -2 m n \\
-m n & m n & \left(m^{2}-n^{2}\right)
\end{array}\right)^{(k)}\left(\begin{array}{c}
\sigma_{x} \\
\sigma_{y} \\
\tau_{x y}
\end{array}\right)^{(k)} .
$$

As can be seen from the physical relationships (1), in multilayer panels with an asymmetric stacking, the layers subjected to tension-compression will cause the panel to bend. Such complex behavior of panels in highly loaded structures can lead to a decrease in their efficiency.

In addition, the formation of such panels will be accompanied by the occurrence of residual thermal bending deformations (warpage).

Panels with a symmetrical arrangement of layers are devoid of this drawback, i.e. when layer $(k)$ corresponds to the same layer $(N-k)$, where $N$ is the total number of layers in the package. With this in mind, we write down expressions for generalized stiffnesses in the following simplified form:

$$
\begin{aligned}
& B_{m n}=2 \sum_{k=1}^{N / 2} b_{m n}{ }^{(k)}\left(Z_{k}-Z_{k-1}\right) \\
& D_{m n}=\frac{2}{3} \sum_{k=1}^{N / 2} b_{m n}{ }^{(k)}\left(Z_{k}{ }^{3}-Z_{k-1}{ }^{3}\right) \\
& C_{m n}=0
\end{aligned}
$$

In this case, the $\mathrm{Zk}$ coordinate is measured from the median plane $\mathrm{e}=\mathrm{h} / 2$, and the sum is calculated only for half of the packet. Physical relations (1) for an orthotropic panel with free from load edges then take the form: 


$$
\begin{aligned}
& \left\{\begin{array}{l}
0=B_{11} \varepsilon_{x}+B_{12} \varepsilon_{y}-N_{x}{ }^{T}-N_{x}{ }^{H} \\
0=B_{12} \varepsilon_{x}+B_{22} \varepsilon_{y}-N_{y}{ }^{T}-N_{y}{ }^{H} \\
0=D_{11} \kappa_{x}+D_{12} \kappa_{y} \\
0=D_{21} \kappa_{x}+D_{22} \kappa_{y}
\end{array}\right. \\
& \left\{\begin{array}{l}
0=B_{33} \varepsilon_{x y}-N_{x y}{ }^{T}-N_{x y}{ }^{H} \\
0=D_{33} \kappa_{x y}
\end{array}\right.
\end{aligned}
$$

From (21) it is easy to see that the formation of flat panels with a symmetric stack structure will not lead to their warping.

The algorithm for analyzing the residual stress-strain state, therefore, can be conditionally divided into four stages:

1. calculation of the stiffness characteristics of the package according to formulas (5), (.7)10) - (.11)14);

2. determination of internal force factors caused by the initial tension and temperature difference according to the formulas (.3)16) -(.6)19);

3 . determination of the components of deformations and curvature from physical relations (1);

4. calculation of stresses in composite layers using Hooke's law (17), (18).

\section{CAlculation Results}

For analytical calculation: the plate is free from fastening and external power load, the temperature load is a drop of $100^{\circ} \mathrm{C}$. For numerical calculation: the plate is fixed at the point of the geometric center, there is no power load, the temperature load is a drop of $100^{\circ} \mathrm{C}$.

The characteristics of the materials used in the simulation are presented in Table 1.

\begin{tabular}{|c|c|c|c|c|c|c|c|c|}
\hline № & & $\begin{array}{c}\mathrm{E}_{11} \\
{[\mathrm{MPa}]}\end{array}$ & $\begin{array}{c}\mathrm{E}_{22} \\
{[\mathrm{MPa}]}\end{array}$ & $\begin{array}{c}\mathrm{G}_{12} \\
{[\mathrm{MPa}]}\end{array}$ & $v_{12}$ & $\begin{array}{c}\alpha_{1} \\
{\left[10^{-6} \mathrm{~K}^{-1}\right]}\end{array}$ & $\begin{array}{c}\alpha_{2}, \alpha_{3} \\
{\left[10^{-6} \mathrm{~K}^{-1}\right]}\end{array}$ & $\begin{array}{c}\mathrm{G}_{23} \\
{[\mathrm{MPa}]}\end{array}$ \\
\hline & Carbon fiber & 129960 & 7056 & 2658 & 0.593 & 0.7 & 42 & 2214 \\
\hline 1 & $\begin{array}{c}\text { Nanomodified } \\
\text { CFRP }\end{array}$ & 135130 & 19078 & 8225 & 0.567 & 3.4 & 44 & 6085 \\
\hline & Carbon fiber & 129510 & 5211 & 1917 & 0.596 & 0.46 & 42 & 1632 \\
\hline 2 & $\begin{array}{c}\text { Nanomodified } \\
\text { CFRP }\end{array}$ & 129760 & 6266 & 2337 & 0.594 & 0.6 & 42 & 1965 \\
\hline & Carbon fiber & 129500 & 4730 & 2050 & 0.29 & 0.19 & 20 & 1670 \\
\hline 3 & $\begin{array}{c}\text { Nanomodified } \\
\text { CFRP }\end{array}$ & 129750 & 5700 & 2500 & 0.29 & 0.26 & 20 & 2010 \\
\hline & Carbon fiber & 129500 & 4730 & 2050 & 0.29 & -10.4 & 20 & 1670 \\
\hline 4 & $\begin{array}{c}\text { Nanomodified } \\
\text { CFRP }\end{array}$ & 129750 & 5700 & 2500 & 0.29 & -12 & 20 & 2010 \\
\hline
\end{tabular}

Table 1. Physical and mechanical characteristics of materials 

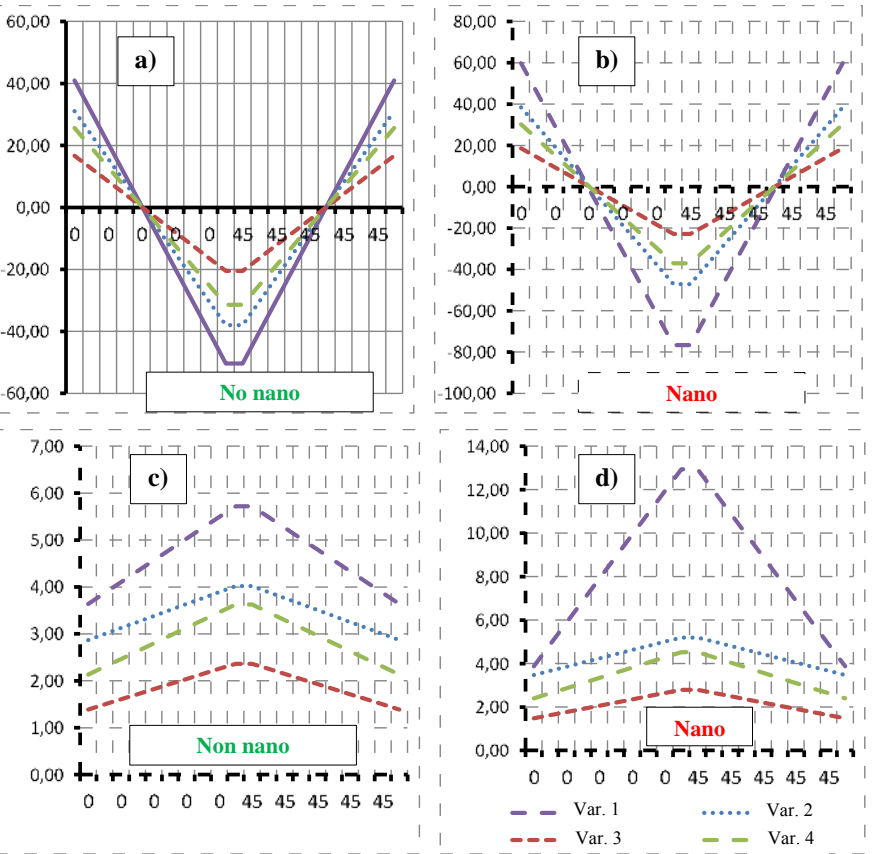

Fig. 3 Results of distribution of normal stresses $\sigma 1(a, b)$ and $\sigma 2(\mathrm{c}, \mathrm{d})$ by layers, MPa for options 1-4 and stacking [010 / 4510].
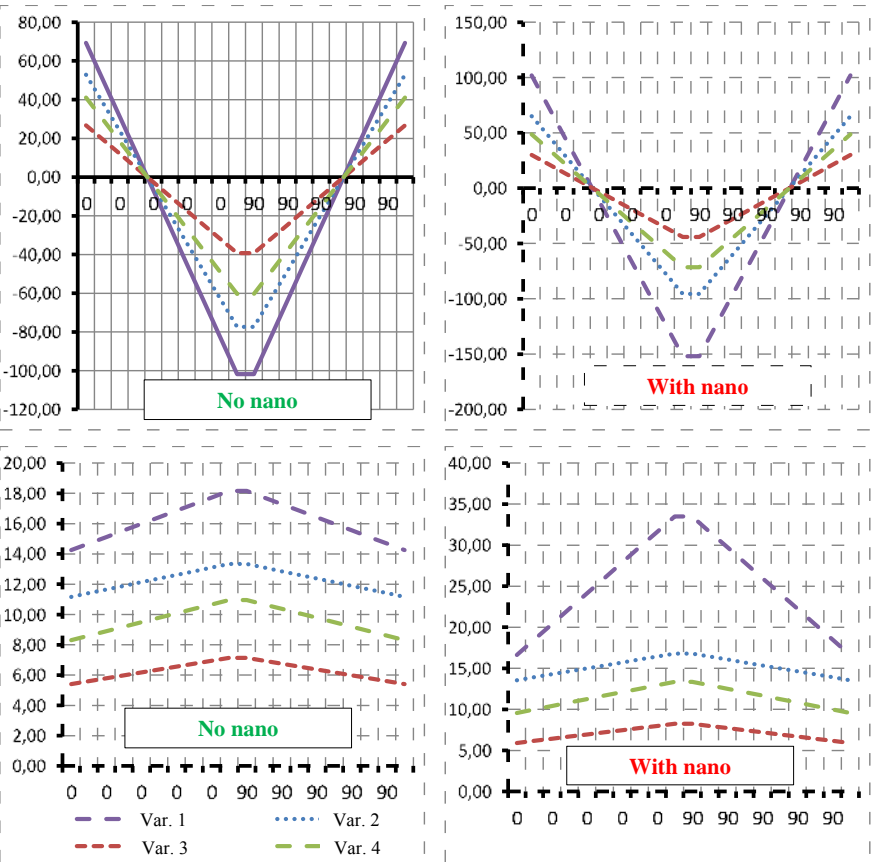

Fig. 4 Results of distribution of normal stresses $\sigma 1(a, b)$ and $\sigma 2(c, d)$ by layers, MPa for options 1-4 and stacking [010/9010].

The results obtained by analytical and numerical methods are identical. To verify the data obtained, a comparison was made between the calculated and the deflections obtained on experimental samples. The greatest similarity with experimental data is provided by method 4 for determining the effective properties of a monolayer.

The results obtained show the possibility of reducing the residual stress-strain rate and leash in structures with asymmetric reinforcement schemes when using a matrix containing carbon nanoparticles. This means that the application of nanomaterials as nanofiller can substantially improve the characteristics of the resulting material. This finding opens prospective for practical application of the model obtained for design and calculation of construction composite materials.

\section{CONCLUSION}

It was shown, that the introduction of nanosized particles into the composition of the composite or its components (fiber or binder) allows not only to increase its physical and mechanical properties, but also to improve the picture of the residual stress-strain state.

The following conclusions are drawn about the possibility of reducing the residual stress-strain state in structures with asymmetric reinforcement schemes when using a matrix containing carbon nanoparticles.

1. A mathematical model of a multilayer panel made of nano-modified carbon fiber with asymmetric packing has been built.

2. A study of the influence of nanomodification of carbon fiber reinforced plastic on the residual stress-strain state after molding was carried out using numerical and analytical methods.

3. Comparison of the results of numerical and analytical modeling with experimental data.

4. Investigation of the residual stress-strain state of structural elements made of carbon fiber reinforced plastic made it possible to reveal the possibility of reducing the residual stress-strain state and leash in structures with asymmetric reinforcement schemes when using a matrix containing carbon nanoparticles.

\section{REFERENCES}

[1] A. N. Astapov, E. L. Kuznetsova, L. N. Rabinskiy, "Operating capacity of anti-oxidizing coating in hypersonic flows of air plasma," Surface Review and Letters, 26(2), pp. 1850145, 2019.

[2] L. N. Rabinskiy, O. V. Tushavina, E. I. Starovoitov, "Study of thermal effects of electromagnetic radiation on the environment from space rocket activity6" INCAS Bulletin, 12 (Special Issue), pp. 141-148, 2020.

[3] A. V. Babaytsev, A. A. Orekhov, L. N. Rabinskiy, "Properties and microstructure of AlSi10Mg samples obtained by selective laser melting," Nanoscience and Technology: An International Journal, 11(3), pp. 213222, 2020.

[4] O. V. Egorova, Y. K. Kyaw, "Solution of inverse nonstationary boundary value problems of diffraction of plane pressure wave on convex surfaces based on analytical solution," Journal of Applied Engineering Science, 18(4), pp. 676-680, 2020.

[5] V. F. Formalev, É. M. Kartashov, S. A. Kolesnik, "On the Dynamics of Motion and Reflection of Temperature Solitons in Wave Heat Transfer in Limited Regions," 
Journal of Engineering Physics and Thermophysics, 93(1), pp. 10-15 (2020).

[6] Y. Sun, O. V. Egorova, E. L. Kuznetsova, "Identification of the front angle of a plane acoustic oblique pressure wave on convex surfaces with the use of analytical solution," Journal of the Balkan Tribological Association, 27(2), pp. 189-197, 2021.

[7] V. F. Formalev, N. A. Bulychev, E. L. Kuznetsova, S. A. Kolesnik, "The Thermal State of a Packet of Cooled Microrocket Gas-Dynamic Lasers," Technical Physics Letters, vol. 46, i. 3, pp. 245-248, 2020.

[8] M. Sha, Y. A. Utkin, O. V. Tushavina, P. F. Pronina, "Experimental studies of heat and mass transfer from tip models made of carbon-carbon composite material (cccm) under conditions of high-intensity thermal load," Periodico Tche Quimica, vol. 17, i. 35, pp. 988-997, 2020.

[9] P. F. Pronina, O. V. Tushavina, E. I. Starovoitov, "Study of the radiation situation in moscow by investigating elastoplastic bodies in a neutron flux taking into account thermal effects," Periodico Tche Quimica, 17(35), pp. 753-764, 2020.

[10]A. A. Orekhov, Y. A. Utkin, P. F. Pronina, "Determination of deformation in mesh composite structure under the action of compressive loads," Periodico Tche Quimica, 17(35), pp. 599-608, 2020.

[11]A. V. Babaytsev, L. N. Rabinskiy, K. T. Aung, "Investigation of the contact zone of a cylindrical shell located between two parallel rigid plates with a gap," INCAS Bulletin, 12(Special Issue), pp. 43-52, 2020.

[12]V. G. Dmitriev, O. V. Egorova, E. I. Starovoitov, "Particularities of mathematical modeling of deformation processes for arched and panel designs of composites with large displacements and rotation angles," INCAS Bulletin, 12(Special Issue), pp. 53-66, 2020.

[13]O. V. Egorova, E. I. Starovoitov, "Non-stationary diffraction problem of a plane oblique pressure wave on the shell in the form of a hyperbolic cylinder taking into account the dissipation effect," INCAS Bulletin, 12(Special Issue), pp. 67-77, 2020.

[14] O. V. Tushavina, "Coupled heat transfer between a viscous shock gasdynamic layer and a transversely streamlined anisotropic half-space" INCAS Bulletin, 12 (Special Issue), pp. 211-220, 2020.

[15] S. Vakhneev, E. Starovoitov, "Damping of circular composite viscoelastic plate vibration under neutron irradiation," Journal of Applied Engineering Science, 18(4), pp. 699-704, 2020.

[16] V. A. Pogodin, L. N. Rabinskii, S. A. Sitnikov, "3D Printing of Components for the Gas-Discharge Chamber of Electric Rocket Engines," Russian Engineering Research, vol. 39, no. 9, pp. 797-799, 2019.

[17] Y. K. Kyaw, E. L. Kuznetsova, A. V. Makarenko, "Complex mathematical modelling of mechatronic modules of promising mobile objects," INCAS Bulletin, 12(Special Issue), pp. 91-98, 2020.

[18] L. E. Kuznetsova, V. G. Fedotenkov, "Dynamics of a spherical enclosure in a liquid during ultrasonic cavitation," Journal of Applied Engineering Science, 18(4), pp. $681-686,2020$.

[19] A. V. Makarenko, E. L. Kuznetsova, "Energy-Efficient Actuator for the Control System of Promising Vehicles," Russian Engineering Research, 39(9), pp. 776-779, 2019.

[20]E. L. Kuznetsova, A. V. Makarenko, "Mathematic simulation of energy-efficient power supply sources for mechatronic modules of promising mobile objects," Periodico Tche Quimica, 15(Special Issue 1), pp. 330338, 2018.

[21] Y. Li, A. M. Arutiunian, E. L. Kuznetsova, G. V. Fedotenkov, "Method for solving plane unsteady contact problems for rigid stamp and elastic half-space with a cavity of arbitrary geometry and location," INCAS Bulletin, 12(Special Issue), pp. 99-113, 2020.

[22]E. L. Kuznetsova, G. V. Fedotenkov, E. I. Starovoitov, "Methods of diagnostic of pipe mechanical damage using functional analysis, neural networks and method of finite elements," INCAS Bulletin, 12 (Special Issue), pp. 79-90, 2020.

[23]Y. K. Kyaw, P. F. Pronina, P. O. Polyakov, "Mathematical modelling of the effect of heat fluxes from external sources on the surface of spacecraft," Journal of Applied Engineering Science, 18(4), pp. 732-736, 2020.

[24] V. F. Formalev, S. A. Kolesnik, B. A. Garibyan, "Mathematical modeling of heat transfer in anisotropic plate with internal sinks," AIP Conference Proceedings, 2181, pp. 020003, 2019.

[25] V. F. Formalev, S. A. Kolesnik, B. A. Garibyan, "Heat transfer with absorption in anisotropic thermal protection of high-temperature products," Herald of the Bauman Moscow State Technical University, Series Natural Sciences, (5), pp. 35-49, 2019.

[26] S. A. Kolesnik, N. A. Bulychev, "Numerical analytic method for solving the inverse coefficient problem of heat conduction in anisotropic half-space," Journal of Physics: Conference Series, 1474(1), pp. 012024, 2020.

[27] V. F. Formalev, N. A. Bulychev, S. A. Kolesnik, M. A. Kazaryan, "Thermal state of the package of cooled gasdynamic microlasers," Proceedings of SPIE - The International Society for Optical Engineering, 11322, article number 113221B, 2019.

[28] V. F. Formalev, S. A. Kolesnik, B. A. Garibyan, "Analytical solution of the problem of conjugate heat transfer between a gasdynamic boundary layer and anisotropic strip," Herald of the Bauman Moscow State Technical University, Series Natural Sciences, 5(92), pp. 44-59, 2020.

[29] Y. Sun, S. A. Kolesnik, E. L. Kuznetsova, "Mathematical modeling of coupled heat transfer on cooled gas turbine blades," INCAS Bulletin, 12(Special Issue), pp. 193-200, 2020.

[30] I. Kurchatov, N. Bulychev, S. Kolesnik, E. Muravev, "Application of the direct matrix analysis method for calculating the parameters of the luminescence spectra of the iron ion in zinc sulfide crystals," AIP Conference Proceedings, 2181, 020015, 2019. 
[31] B. A. Antufev, E. L. Kuznetsova, L. N. Rabinskiy, O. V. Tushavina, "Investigation of a complex stress-strain state of a cylindrical shell with a dynamically collapsing internal elastic base under the influence of temperature fields of various physical nature," Asia Life Sciences, (2), pp. 689-696, 2019.

[32] B. A. Antufev, E. L. Kuznetsova, L. N. Rabinskiy, O. V. Tushavina, "Complex stressed deformed state of a cylindrical shell with a dynamically destructive internal elastic base under the action of temperature fields of various physical nature," Asia Life Sciences, (2), pp. 775782, 2019.

[33] L. N. Rabinskiy, O. V. Tushavina, "Problems of land reclamation and heat protection of biological objects against contamination by the aviation and rocket launch site," Journal of Environmental Management and Tourism, 10(5), pp. 967-973, 2019.

[34]A. N. Astapov, I. P. Lifanov, L. N. Rabinskiy, "Perspective Heat-Resistant Coating for Protection of $\mathrm{Cf} / \mathrm{SiC}$ Composites in Air Plasma Hypersonic Flow," High Temperature, 57(5), pp. 744-752, 2019.

[35] V. N. Dobryanskiy, L. N. Rabinskiy, O. V. Tushavina, "Validation of methodology for modeling effects of loss of stability in thin-walled parts manufactured using SLM technology," Periodico Tche Quimica, 16(33), pp. 650656, 2019.

[36] V. F. Formalev, S. A. Kolesnik, I. A. Selin, "Local nonequilibrium heat transfer in an anisotropic half-space affected by a non-steady state point heat source," Herald of the Bauman Moscow State Technical University, Series Natural Sciences, 80(5), pp. 99-111, 2018.

[37] S. A. Kolesnik, N. A. Bulychev, L. N. Rabinskiy, M. A. Kazaryan, "Mathematical modeling and experimental studies of thermal protection of composite materials under high-intensity effects of laser radiation," Proceedings of SPIE - The International Society for Optical Engineering, 11322, article number 113221R, 2019.

[38] O. A. Pashkov, "Influence of Polymer Coatings on the Mechanical Properties of Steel Samples in Tensile and Bending Tests," Studies in Systems, Decision and Control, to be published.

[39] O. A. Pashkov, "Investigation of the Effect of Steel Plate Size and Elevated Temperature on Critical Load in Stability Tests," Studies in Systems, Decision and Control, to be published.

[40] O. A. Pashkov, "Theoretical calculation of the thickness of interphase zones in the Al-A12O3 composite," Studies in Systems, Decision and Control, to be published.

[41] O. A. Pashkov, "Experimental and Theoretical Study of Mechanical Properties of Matrix Composite Materials," Studies in Systems, Decision and Control, to be published.

[42]E. L. Kuznetsova, L. N. Rabinskiy, "Heat transfer in nonlinear anisotropic growing bodies based on analytical solution," Asia Life Sciences, (2), pp. 837-846, 2019.

[43] E. L. Kuznetsova, L. N. Rabinskiy, "Numerical modeling and software for determining the static and linkage parameters of growing bodies in the process of non- stationary additive heat and mass transfer," Periodico Tche Quimica, 16(33), pp. 472-479, 2019.

[44] O. A. Butusova, "Chemical and Physical Properties of Magnetic Composite Materials," Studies in Systems, Decision and Control, to be published.

[45] O. A. Butusova, "Investigation of Adsorption Capacity of Magnetic Sorbents for Medical Application," Studies in Systems, Decision and Control, to be published.

[46]M. O. Kaptakov, "Enhancement of Physical and Mechanical Properties of Metal Surfaces Coated by Polymers," Studies in Systems, Decision and Control, to be published.

[47] B. A. Garibyan, "Determination of the Elastic Modulus of the Coating Using a Spherical Indenter," Studies in Systems, Decision and Control, to be published.

[48] M. O. Kaptakov, "Calculation of Physical and Mechanical Parameters of Metal Samples with Polymer Layers," Studies in Systems, Decision and Control, to be published.

[49] B. A. Garibyan, "Theoretical Estimations of Influence of Polymer Coatings on the Elastic Modulus and Ultimate Strength of Steel Samples," Studies in Systems, Decision and Control, to be published.

[50] M. O. Kaptakov, "Numerical and Analytical Study of Mechanical Characteristics of Nanocomposites Based on Carbon Additives," Studies in Systems, Decision and Control, to be published.

[51]M. O. Kaptakov, "Synthesis and Investigation of Composite Materials Reinforced with Carbon Wires," Studies in Systems, Decision and Control, to be published.

[52]E. L. Kuznetsova, L. N. Rabinskiy, "Linearization of radiant heat fluxes in the mathematical modeling of growing bodies by the action of high temperatures in additive manufacturing," Asia Life Sciences, (2), pp. 943954, 2019.

[53] A. V. Babaytsev, E. L. Kuznetsova, L. N. Rabinskiy, O. V. Tushavina, "Investigation of permanent strains in nanomodified composites after molding at elevated temperatures," Periodico Tche Quimica, 17(34), pp. 1055-1067, 2020.

[54] L. N. Rabinsky, E. L. Kuznetsova, "Simulation of residual thermal stresses in high-porous fibrous silicon nitride ceramics," Powder Metallurgy and Metal Ceramics, 57(11-12), pp. 663-669, 2019.

[55]L. N. Rabinskiy, "Non-stationary problem of the plane oblique pressure wave diffraction on thin shell in the shape of parabolic cylinder," Periodico Tche Quimica, 16(32), pp. 328-337, 2019.

[56] V. N. Dobryanskiy, L. N. Rabinskiy, O. V. Tushavina, "Experimental finding of fracture toughness characteristics and theoretical modeling of crack propagation processes in carbon fiber samples under conditions of additive production," Periodico Tche Quimica, 16(33), pp. 325-336, 2019.

[57] O. A. Butusova, "Surface Modification of Titanium Dioxide Microparticles Under Ultrasonic Treatment," International Journal of Pharmaceutical Research, vol. 12, i. 4, pp. 2292-2296, 2020. 
[58] O. A. Butusova, "Stabilization of Carbon Microparticles by High-Molecular Surfactants," International Journal of Pharmaceutical Research, vol. 12, Supplementary Issue 2, pp. 1147-1151, 2020.

[59] Yu. V. Ioni, A. Ethiraj, "New Tailor-Made Polymer Stabilizers for Aqueous Dispersions of Hydrophobic Carbon Nanoparticles," International Journal of Pharmaceutical Research, vol. 12, i. 4, pp. 3443-3446, 2020.

[60] Yu. V. Ioni, "Nanoparticles of noble metals on the surface of graphene flakes," Periodico Tche Quimica, vol. 17, no. 36, pp. 1199-1211, 2020.

[61] O. A. Butusova, "Vinyl Ether Copolymers as Stabilizers of Carbon Black Suspensions," International Journal of Pharmaceutical Research, vol. 12, Supplementary Issue 2, pp. 1152-1155, 2020.

[62] M. O. Kaptakov, "Catalytic Desulfuration of Oil Products under Ultrasonic Treatment," International Journal of Pharmaceutical Research, vol. 12, Supplementary Issue 2, pp. 1838-1843, 2020.

[63] B. A. Garibyan, "Enhancement of Mechanical Properties of Inorganic Glass under Ultrasonic Treatment," International Journal of Pharmaceutical Research, vol. 12, Supplementary Issue 2, pp. 1829-1832, 2020.

[64]M. O. Kaptakov, "Enhancement of Quality of Oil Products under Ultrasonic Treatment," International Journal of Pharmaceutical Research, vol. 12, Supplementary Issue 2, pp. 1851-1855, 2020.

[65]O. A. Butusova, "Adsorption Behaviour of Ethylhydroxyethyl Cellulose on the Surface of Microparticles of Titanium and Ferrous Oxides," International Journal of Pharmaceutical Research, vol. 12, Supplementary Issue 2, pp. 1156-1159, 2020.

[66]A. N. Tarasova, "Vibration-based Method for Mechanochemical Coating Metallic Surfaces," International Journal of Pharmaceutical Research, vol. 12, Supplementary Issue 2, pp. 1160-1168, 2020.

[67]B. A. Garibyan, "Mechanical Properties of Electroconductive Ceramics," International Journal of Pharmaceutical Research, vol. 12, Supplementary Issue 2, pp. 1825-1828, 2020.

[68]M. O. Kaptakov, "Effect of Ultrasonic Treatment on Stability of $\mathrm{TiO}_{2}$ Aqueous Dispersions in Presence of Water-Soluble Polymers," International Journal of Pharmaceutical Research, vol. 12, Supplementary Issue 2, pp. 1821-1824, 2020.

[69] Yu. V. Ioni, "Synthesis of Metal Oxide Nanoparticles and Formation of Nanostructured Layers on Surfaces under Ultrasonic Vibrations," International Journal of Pharmaceutical Research, vol. 12, i. 4, pp. 3432-3435, 2020.

[70]A. N. Tarasova, "Effect of Reagent Concentrations on Equilibria in Water-Soluble Complexes," International Journal of Pharmaceutical Research, vol. 12, Supplementary Issue 2, pp. 1169-1172, 2020.

[71]A. N. Tarasova, "Effect of Vibration on Physical Properties of Polymeric Latexes," International Journal of
Pharmaceutical Research, vol. 12, Supplementary Issue 2, pp. 1173-1180, 2020.

[72] Yu. V. Ioni, A. Ethiraj, "Study of Microparticles Surface Modification by Electrokinetic Potential Measuring," International Journal of Pharmaceutical Research, vol. 12, i. 4, pp. 3436-3439, 2020.

[73] Yu. V. Ioni, "Effect of Ultrasonic Treatment on Properties of Aqueous Dispersions of Inorganic and Organic Particles in Presence of Water-Soluble Polymers," International Journal of Pharmaceutical Research, vol. 12, i. 4, pp. 3440-3442, 2020.

[74] L. N. Rabinskiy, O. V. Tushavina, V. F. Formalev, "Mathematical modeling of heat and mass transfer in shock layer on dimmed bodies at aerodynamic heating of aircraft," Asia Life Sciences, (2), pp. 897-911, 2019.

[75]B. A. Antufev, O. V. Egorova, L. N. Rabinskiy, "Quasistatic stability of a ribbed shell interacting with moving load," INCAS Bulletin, 11, pp. 33-39, 2019.

[76] V. V. Bodryshev, A. V. Babaytsev, L. N. Rabinskiy, "Investigation of processes of deformation of plastic materials with the help of digital image processing", Periodico Tche Quimica, 16(33), pp. 865-876, 2019.

[77]L. N. Rabinskiy, S. A. Sitnikov, "Development of technologies for obtaining composite material based on silicone binder for its further use in space electric rocket engines," Periodico Tche Quimica, 15(Special Issue 1), pp. 390-395, 2018.

\section{Contribution of Individual Authors to the Creation} of a Scientific Article (Ghostwriting Policy)

S. Radaev carried out modelling and calculations.

\section{Creative Commons Attribution License $\mathbf{4 . 0}$} (Attribution 4.0 International, CC BY 4.0)

This article is published under the terms of the Creative Commons Attribution License 4.0

https://creativecommons.org/licenses/by/4.0/deed.en_US 